\title{
Discussion: Synthesis of a benchmark exercise for geotechnical analysis of a thermoactive pille
}

Julien Habert Ing.
Senior Engineer, Cerema Nord-Picardie, Lille, France

Hussein Mroueh PhD, Ing.

Professor, Laboratory of Civil Engineering and Geo-environment of Lille,

University of Lille Science and Technologies, Villeneuve d'Ascq, France

Josif Josifovski PhD, Ing.

Associate Professor, Department of Geotechnics, Faculty of Civil Engineering, Ss Cyril and Methodius University, Skopje, Republic of Macedonia

\section{Witold Bogusz MSc Eng}

Research Assistant, Department of Building Structures, Geotechnics and Concrete, Building Research Institute, Warsaw, Poland (Orcid:0000-00026266-342X)

\section{Contribution by P. J. Bourne-Webb}

Habert et al. (2020) have presented an interesting comparison of a set of independent analyses of the problem of a thermally activated pile in sand. The objective of the benchmarking exercise was to explore the calculation methods and assumptions made in different parts of Europe, in relation to the analysis and design of thermally activated piles, and was undertaken as part of European Cooperation in Science and Technology Action TU1405 - the European network for shallow geothermal energy applications in buildings and infrastructures (Gabi).

This discussion hopes to enrich the value of the benchmark exercise by putting the results into context with some recently published works by Bourne-Webb et al. (2019). and BourneWebb and Bodas Freitas (2020). These papers collated the results of various large- and small-scale tests and numerical modelling studies that have been published in recent years and sought to provide some synthesis of the outcomes to inform researchers and designers better as to what behaviours might be expected from thermally activated pile foundations.

Figure 10 compares the thermal effects reported in Tables 4 and 5 of Habert et al. (2020) with the results collated in the paper by Bourne-Webb et al. (2019). In the figure, the thermal stress changes, $\sigma_{\mathrm{th} \text { max }}$, have been normalised by the stress that would be mobilised if the pile, acting as a column, was perfectly restrained - that is, $\sigma_{\text {th,fixed }}=\alpha \Delta T E_{\mathrm{c}}-$ and the pile head movement, $y_{\mathrm{th}, 0}$, is normalised by the thermal movement of the pile acting as an unrestrained column, $y_{\mathrm{th} \text {,free }}=\alpha \Delta T L$, where $\alpha$ is the pile coefficient of thermal expansion, $\Delta T$ is the change in the temperature of the pile (assumed uniform), $E_{\mathrm{c}}$ is the Young's modulus of the pile and $L$ is the pile length.

In Figure 10, it is apparent that during cooling (circular symbols), the pile head tends to move more than when it is heated (square symbols) and that the thermal stress changes are slightly smaller.

\author{
Donatella Sterpi PhD \\ Associate Professor, Department of Civil and Environmental Engineering, \\ Politecnico di Milano, Milan, Italy \\ Konstantinos Georgiadis Dipl.(Eng), MSc, PhD, DIC \\ Associate Professor, Department of Civil Engineering, Aristotle University of \\ Thessaloniki, Thessaloniki, Greece \\ Peter J. Bourne-Webb PhD, CEng, MICE, CEngNZ \\ Auxiliary Professor, Civil Engineering Research and Innovation for \\ Sustainability, Instituto Superior Técnico, Universidade de Lisboa, Lisbon, \\ Portugal (Orcid:0000-0003-1203-4710) (corresponding author: \\ peter.bourne-webb.co.uk@tecnico.ulisboa.pt)
}

This is expected based on the collated results in the paper by Bourne-Webb and Bodas Freitas (2020). In discussing this aspect of the behaviour, Bourne-Webb and Bodas Freitas (2020) concluded that the larger movements during cooling, compared with heating, were consistent with the extended framework for single pile thermal response that they discussed - that is, during heating, the depth to the neutral point (where the pile-soil relative movement is zero) will reduce, as will $y_{\text {th, },}$, while during cooling, the reverse occurs: the neutral point moves down and $y_{\text {th }, 0}$ increases.

There are obvious differences between the analyses presented by Habert et al. (2020) and the field test results (grey circles, Figure 10). However, these are perhaps largely due to the latter having been undertaken on piles in rather stiff soils that generate significant shaft resistance, rather than sand where the shaft resistance and hence pile shaft restraint are generally smaller. The comparison with the model tests (grey squares) and other numerical analyses (grey triangles) is rather better, and this may be because the majority of these have been undertaken in or assuming that the soil modelled behaves as a frictional material, as was the case in the paper by Habert et al. (2020), for which the restraint generated on the shaft is somewhat smaller and movements are larger.

The limit on thermal stress response due to the low mobilised shaft resistance can be quantified with a few simple assumptions regarding the load-transfer behaviour between the pile and soil (Bourne-Webb et al., 2016). In Figure 11, the ratios represented by lines (1) and (2) are for the fixed-head case $\left(y_{\mathrm{th}, 0} / y_{\mathrm{th}, \text { free }}=0\right)$ and represent the range of ultimate shaft resistance values used by the contributors to the benchmarking exercise. The calculation of these ratios assumes that the shaft resistance is fully mobilised at a displacement of $1.0 \%$ of the pile diameter. Line (3) is equivalent to (2) but assumes that cooling invokes a stiffer (in effect unloading) response and the shaft resistance is fully mobilised at a 


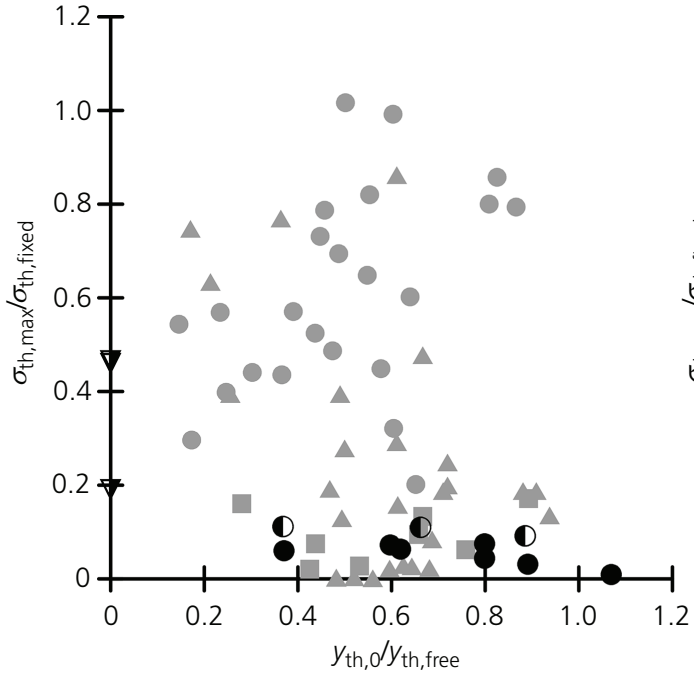

- Observed: large scale - Observed: small scale

- Observed: numerical
- Cooling: free head

- Cooling: partially restrained

$\nabla$ Cooling: fixed head

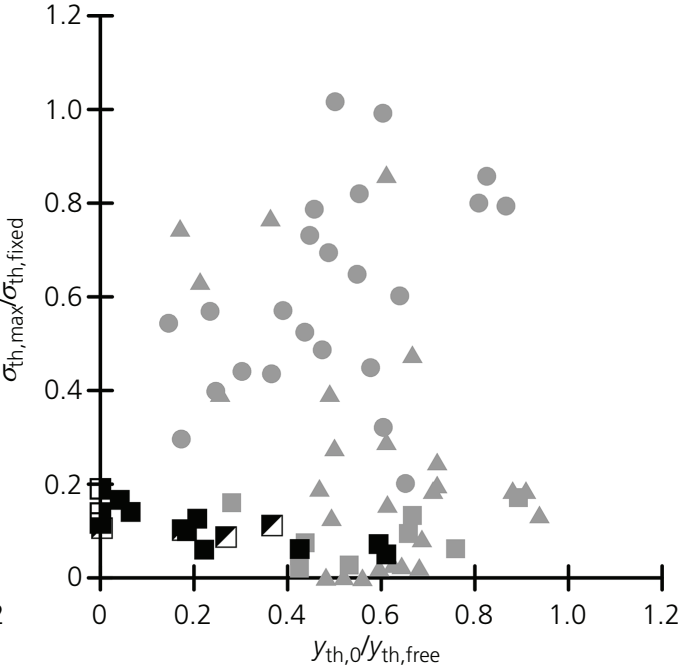

- Heating: free head

$\square$ Heating: partially restrained

प Heating: fixed head

Figure 10. Comparison of benchmark energy pile thermal response predictions against collated results in the paper by Bourne-Webb et al. (2019)

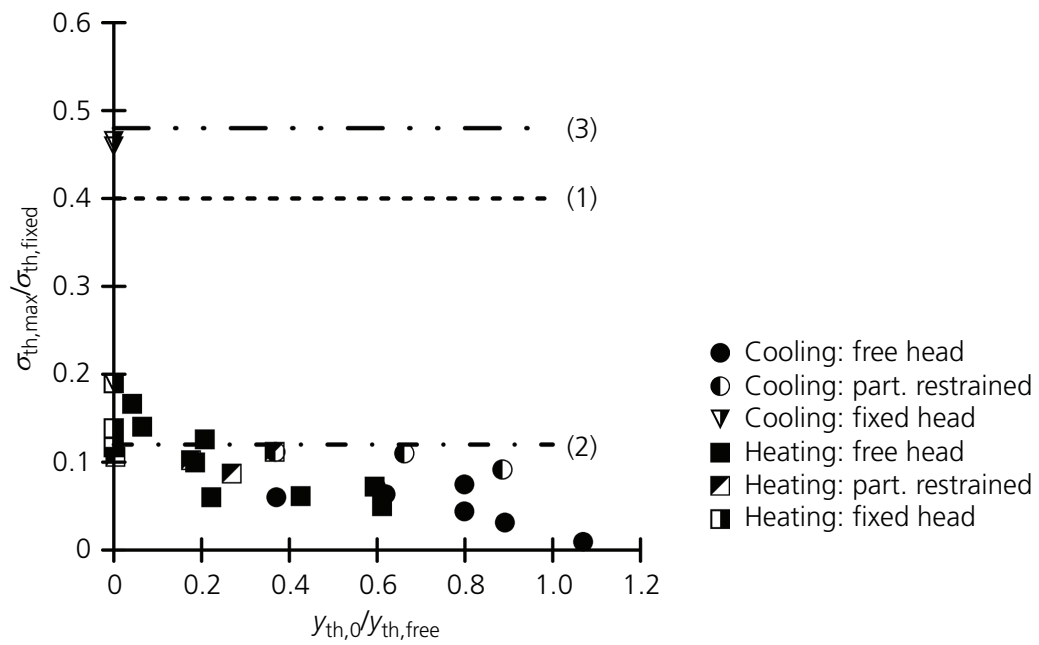

Figure 11. Effect of shaft resistance assumptions on mobilised stress

displacement of $0.2 \%$ of the pile diameter. The position of these lines also depends on the pile Young's modulus used, with lower values shifting the lines upwards, but it is clear that the pile thermal stress response predicted in the benchmark exercise can be bounded reasonably well using simple hand calculations.

To be consistent with the approach taken in BS EN 1997-1:2004 (BSI, 2004) when ground movement - for example, downdrag and heave - creates additional forces within a pile, when assessing the thermally induced stress response of a thermally activated pile, it is important to understand that an upper value to the pile shaft resistance (not the lower value used to design for conventional load resistance) must be used to ensure that the action effects due to the pile thermal expansion and contraction are not underestimated. BS EN 1997-1:2004 utilises a multiplier on the soil characteristic strength to achieve this; however, guidance is needed to confirm whether this approach is appropriate.

While the above will lead to a value of the thermally induced stress that is compliant with BS EN 1997-1:2004, there is an 
Environmental Geotechnics

Volume 10 issue 2
Discussion: Synthesis of a benchmark

exercise for geotechnical analysis of a

thermoactive pile

Habert, Mroueh, Josifovski et al. incompatibility if this is then used to evaluate the pile deformations, as the upper value for the shaft resistance will result in reduced pile head deformation. However, pile movement is a serviceability condition and the un-factored characteristic soil parameters should be used in any such evaluation.

The benchmarking exercise has been useful in highlighting that design guidance relating to thermally activated foundations must be very clear in terms of how the differing limit state verifications should be carried out. What this discussion has intended to highlight was that a first-order estimate of the possible effect of thermal loading on a pile foundation can be made with a few simple assumptions and limited calculation. Then, if this suggests that the behaviours might be of concern, then a more complex analysis may be warranted.

\section{REFERENCES}

Bourne-Webb PJ and Bodas Freitas TM (2020) Thermally-activated piles and pile groups under monotonic and cyclic thermal loading - a review. Renewable Energy 147(Part 2): 2572-2581, https://doi.org/10. 1016/j.renene.2018.11.025.

Bourne-Webb PJ, Bodas Freitas TM and Freitas Assunção RM (2016) Soil-pile thermal interactions in energy foundations. Géotechnique 66(2): 167-171, https://doi.org/10.1680/jgeot.15.T.017.

Bourne-Webb PJ, Bodas Freitas TM and Freitas Assunção RM (2019) A review of pile-soil interactions in isolated, thermally-activated piles. Computers and Geotechnics 108: 61-74, https://doi.org/10.1016/j. compgeo.2018.12.008.

BSI (2004) BS EN 1997-1:2004: Eurocode 7. Geotechnical design. General rules. BSI, London, UK.

Habert J, Mroueh H, Josifovski J et al. (2020) Synthesis of a benchmark exercise for geotechnical analysis of a thermoactive pile. Environmental Geotechnics 7(4): 225-236, https://doi.org/10.1680/ jenge.18.00054.

\section{How can you contribute?}

To discuss this paper, please submit up to 500 words to the editor at journals@ice.org.uk. Your contribution will be forwarded to the author(s) for a reply and, if considered appropriate by the editorial board, it will be published as a discussion in a future issue of the journal. 